\title{
The effects of acute acetaminophen toxicity on hepatic mRNA expression of SOD, CAT, GSH-Px, and levels of peroxynitrite, nitric oxide, reduced glutathione, and malondialdehyde in rabbit
}

Yilmaz Cigremis $\cdot$ Huseyin Turel $\cdot$ Kevser Adiguzel $\cdot$

Muslum Akgoz · Asim Kart · Musa Karaman ·

Hasan Ozen

Published online: 17 April 2009

(C) Springer Science+Business Media, LLC. 2009

Erratum to: Mol Cell Biochem (2009) 323:31-38, published online December 29, 2008 DOI 10.1007/s11010-008-9961-8

In Table 2, on the fourth row at the very right end, AST enzyme activity for AAP-treated group should be $49.8 \pm 10.1$ instead of $9.8 \pm 10.01$. For more clarity we print the correct version of the table:
Table 2 Biochemical alterations in control and AAP-treated rabbits

\begin{tabular}{lcc}
\hline Parameter & Control $(n=6)$ & AAP $(n=6)$ \\
\hline GSH $(\mu \mathrm{mol} / \mathrm{gwt})$ & $7.2 \pm 0.5$ & $4.5 \pm 1.0^{*}$ \\
MDA (nmol/gwt) & $21.5 \pm 3.2$ & $35.6 \pm 9.9^{*}$ \\
NO $(\mathrm{nmol} / \mathrm{gwt})$ & $141.7 \pm 20.4$ & $258.3 \pm 56.3^{*}$ \\
AST $(\mathrm{U} / \mathrm{l})$ & $22.8 \pm 2.2$ & $49.8 \pm 10.1^{*}$ \\
ALT $(\mathrm{U} / \mathrm{l})$ & $29.4 \pm 5.9$ & $58.0 \pm 5.1^{*}$ \\
\hline
\end{tabular}

* Significant AAP effect compared to control at $P<0.05$

The online version of the original article can be found under doi: 10.1007/s11010-008-9961-8.

Y. Cigremis $(\bowtie) \cdot K$. Adiguzel

Department of Biology, Faculty of Science and Arts,

Kafkas University, 36100 Kars, Turkey

e-mail: yilmazcigremis@hotmail.com

H. Turel · M. Akgoz

Department of Chemistry, Faculty of Science and Arts,

Kafkas University, 36100 Kars, Turkey

A. Kart

Department of Pharmacology and Toxicology,

College of Veterinary Medicine, Kafkas University,

36100 Kars, Turkey

M. Karaman · H. Ozen

Department of Pathology, College of Veterinary Medicine,

Kafkas University, 36100 Kars, Turkey 